\title{
Owning One's Intellectual Limitations: A Review of Intellectual Humility
}

\author{
Jian $\mathrm{Du}^{1^{*}}$, Yin $\mathrm{Cai}^{2}$ \\ ${ }^{1}$ Graduate School of Human-Environment Studies, Kyushu University, Fukuoka, Japan \\ ${ }^{2}$ Graduate School of Design, Kyushu University, Fukuoka, Japan \\ Email: *dujian122@gmail.com
}

How to cite this paper: Du, J., \& Cai, Y. (2020). Owning One's Intellectual Limitations: A Review of Intellectual Humility. Psychology, 11, 1009-1020.

https://doi.org/10.4236/psych.2020.117066

Received: June 4, 2020

Accepted: July 14, 2020

Published: July 17, 2020

Copyright (c) 2020 by author(s) and Scientific Research Publishing Inc. This work is licensed under the Creative Commons Attribution International License (CC BY 4.0).

http://creativecommons.org/licenses/by/4.0/

\begin{abstract}
In recent years, intellectual humility $(\mathrm{IH})$ has become an emerging topic in psychological research. In general, it refers to the admission and acceptance that one's knowledge is limited, and one's cognitive ability is imperfect. IH has been proven to be associated with many psychological attributes, such as Big Five, rational and objective thinking, academic achievement, and interpersonal relationships, et al. This article systematically reviews the definitions, characteristics, and measurements of $\mathrm{IH}$, the factors influencing it, as well as its psychological functioning. Finally, we suggest that further research should investigate the relationship among the components of $\mathrm{IH}$, and the inconsistent results in this area to clarify the factors mainly influencing IH and the mechanism of IH judgment.
\end{abstract}

\section{Keywords}

Intellectual Humility, Definition and Characteristics, Measurement, Psychological Functioning

\section{Introduction}

Over the years, humility as a virtue has been studied from many perspectives. As opposed to arrogant people, humble people tend to assess their abilities and achievements more accurately. They admit their imperfections and limitations, maintain an openness to conflicting information, are low self-focus and high other-focus, and appreciate the value of everything (Chancellor \& Lyubomirsky, 2013; Tangney, 2000; Wright et al., 2017). In recent years, research on humility has been developed into more specific domains, for example, relational humility (Davis et al., 2011), cultural humility (Hook, Davis, Owen, Worthington Jr., \& Utsey, 2013), spiritual humility (Davis et al., 2010) and so on. The forms of hu- 
mility mentioned above can be seen as the moral dimension of virtues; however, virtues can not only be moral, but can also have an intellectual dimension (Baehr, 2011). Intellectual humility (IH) is a groundbreaking field of study that combines these two dimensions. It entails admitting and accepting that one's knowledge and cognitive ability is limited and imperfect.

Theologians and philosophers have discussed IH from the perspective of virtue (Wang \& Yang, 2019; Whitcomb et al., 2017). However, with the prevalence of positive psychology, IH has become one of the most exciting fields in psychological research because it has been shown to have a wide-reaching influence on human functioning (e.g., Krumrei-Mancuso, 2016). Nevertheless, the study on $\mathrm{IH}$ is still in its early stages, and the progress in understanding IH has been hampered by diverse and multifaceted definitions and measurements of it (Krumrei-Mancuso \& Rouse, 2016). Furthermore, there are also some inconsistent results in this area. In the following, we will review and comb the theoretical and empirical research on IH in order to outline the adumbration of the current state of this research area and give suggestions and directions for future research.

\section{Definition and Characteristics}

IH has been defined by different psychological researchers as, "insight of the limits of one's knowledge" (McElroy et al., 2014); "a nonthreatening awareness of one's intellectual fallibility" (Krumrei-Mancuso \& Rouse, 2016); “recognizing that a particular personal belief may be fallible, accompanied by an appropriate attentiveness to limitations in the evidentiary basis of that belief and to one's own limitations in obtaining and evaluating relevant information" (Leary et al., 2017), et al. To summarize, the essential characteristic of IH is "recognizing that one's beliefs and knowledge may be incorrect or limited".

Whitcomb et al. (2017) further explained that there are four essential characteristics of IH: cognitive responses, behavioral responses, motivational responses, and affective responses. Firstly, one must recognize and accept one's intellectual limitations and the adverse outcomes that may result from them. Secondly, as the desired behavioral result, admit one's intellectual limitations to others in order to correct them and compensate for them. For example, one should be able to adjust his or her viewpoints and respond accordingly to new information. Thirdly, one must be motivated to access his or her intellectual strengths and weaknesses and be willing to revise as needed. Fourthly, a person's affective responses should be emotionally appropriate. For example, regret or depression can be acceptable, but not hostility. From another perspective, Samuelson et al. (2015) suggest that IH has epistemic and social dimensions. Epistemic dimension refers to seeking the truth, pursuing knowledge, such as a desire to learn, curiosity, and inquisitiveness, amongst others. The social dimensions can further be divided into two aspects: the intrapersonal aspect, which refers to how one sees oneself (not showing off, boasting, pretentious et al.) and the interper- 
sonal aspect, which refers to how one interacts with others (unselfish, honest, and polite et al.). These two dimensions have been proven to be two different basic processes (Danovitch, Fisher, Schroder, Hambrick, \& Moser, 2019).

Like self-esteem, IH can be seen as a trait that varies from one individual to another, i.e., in general, how intellectually humble an individual is in different situations and at different times. It also can be seen as a state that changes within persons, i.e., how intellectually humble an individual is in a specific situation or at a specific time (Zachry et al., 2018). Therefore, we can conclude that IH is constant to some extent but may change at a given time due to internal or external factors. Furthermore, like self-efficacy, IH can be general or specific. General $\mathrm{IH}$ varies from one individual to another. At the same time, an individual can be intellectually humble to some beliefs, but intellectually arrogant to other beliefs (Hoyle, Davisson, Diebels, \& Leary, 2016).

Regarding the relationship between IH and other conceptions, there is a spectrum between intellectual arrogance or dogmatism and intellectual servility or timidity. IH is a delicate balance in this spectrum (Haggard et al., 2018; Hazlett, 2012; Wang \& Yang, 2019). Furthermore, it has been suggested that IH is conceptually different from other psychological attributes, such as dogmatism, belief superiority, openness, attitude correctness, and uncertainty about what one believes, just to name a few (Leary et al., 2017).

\section{Measurement}

As mentioned above, the characteristics and internal composition of IH are the subjects of ongoing research, which has led us to the diversity of IH measurement. Each of the measurements is based on different conceptualizations or theories and measures different aspects of IH. These measurements can be categorized as follows.

\subsection{Self-Report Measure}

Based on the conceptualization of Meagher, Leman, Bias, Latendresse, \& Rowatt (2015), Haggard and her associates $(2016,2018)$ developed a 12 -item IH scale (e.g., "I am quick to acknowledge my intellectual limitations"), which measures three main components of IH: owning one's intellectual limitations, appropriate discomfort with intellectual limitations, and love of learning. Each component has 4 items. This scale has good test-retest reliability, convergent validity, and incremental validity, but its discriminant validity is unsatisfactory (Haggard, 2016; Haggard et al., 2018). Krumrei-Mancuso \& Rouse (2016) developed a 22-item scale (e.g., "I am open to revising my important beliefs in the face of new information."), including four factors: independence of intellect and ego (5 items), openness to revising one's viewpoint (5 items), respect for others' viewpoints ( 6 items), and lack of intellectual overconfidence (6 items). This scale has good internal consistency and test-retest reliability and construct validity. Besides these multidimensional scales, Porter \& Schumann (2018) developed a 
9-item unidimensional scale (e.g., "I try to reflect on my weaknesses in order to develop my intelligence"), with 6 positively-worded and 3 negatively-worded items.

Leary and his associates distinguished general $\mathrm{IH}$ from specific $\mathrm{IH}$ and developed scales separately. The general IH scale includes unidimensional 6 items (e.g., "I reconsider my opinions when presented with new evidence"), which is proven not to be contaminated by socially desirable responses (Leary et al., 2017). The specific IH scale includes three-dimensional items, with each dimension having 3 items, for a total of 9 items. The abbreviated version only consists of 3 items. It can measure specific IH based on various beliefs, topics, or issues by inserting keywords into the item stem (e.g., "My views about today may someday turn out to be wrong.") (Hoyle et al., 2016). Relationships between the general IH and several kinds of specific IH (e.g., politics, religion, and education, et al.) were also investigated using these two scales, and only slight correlations were found.

Zachry et al. (2018) distinguished between trait IH and state IH and developed a scale to measure them by only changing verb tense (e.g., for trait IH: "I view the challenging of my ideas as an opportunity to grow and learn" \& for state $\mathrm{IH}$ : "I viewed the challenging of my ideas as an opportunity to grow and learn"). This scale has been proven to have only one factor and good convergent and discriminant validity. Moreover, its predictive validity is as good as other IH scales. Using this scale, Zachry et al. demonstrated that there is much IH variability across situations and time within-person, and this kind of variability is even higher than the variability between-persons. This result has also been supported by other researchers (Meagher et al., 2015).

\subsection{Informant-Report Measure}

Although introspection and self-report can be useful in analyzing many psychological attributes, it may be not adequate for $\mathrm{IH}$. Because $\mathrm{IH}$ is a kind of virtues, self-report measures of IH may be strongly influenced by socially desirable responses or the tendency to enhance oneself (Meagher et al., 2015). Therefore, the informant-report measure may be an important tool for a more objective evaluation of IH. The following two scales were developed to evaluate the perception of others' IH: Firstly, Hook et al. (2015) adapted the cultural humility scale (Hook et al., 2013) to a 12-item IH scale (e.g., "Thinks he/she understands more than he/she actually does"), including two factors: positive other-oriented characteristics (7 items), and superiority and making assumptions (5 items). Secondly, McElroy et al. (2014) developed a 16-item scale from the perspective of interpersonal relationships (e.g., "Has little patience for others' beliefs"), including two factors: intellectual openness (7 items) and intellectual arrogance (9 items). This scale has great internal consistency, reliability, and discriminant validity.

\subsection{Self- and Informant-Report Measure}

Some scales can be used for both self- and informant-report $\mathrm{IH}$ measure. As an 
abbreviated measurement, Meagher et al. (2015) developed a 4-item scale, i.e., "Open to criticism of ideas", "Knows what he/she is not good at", "Can learn from others", and "Is intellectually humble". However, using this scale, the correlation between self- and informant-report IH was not significant. Furthermore, Alfano et al. (2017) developed a multidimensional scale to measure the four factors of IH: open-mindedness, intellectual modesty, corrigibility, and engagement (e.g., "Being smarter than other people is not especially important to me/him"). This scale has been proven to have good construct validity, and four subscales related to various psychological variables in different forms, which shows the necessity to distinguish them. Consistency between self- and informant-report IH obtained by this scale is also not high, but more acceptable (for four subscales, $r \mathrm{~s}=0.28-0.47$ ). This scale is proven applicable across cultures, as has been demonstrated by its use in Germany (Alfano et al., 2017).

\section{Features}

Intellectually humble people possess unique features relating to their cognitive abilities, personalities, and mindset.

On cognitive ability, Samuelson et al. (2015) used open-ended IH measurement and demonstrated that in people's lay theory, the intellectually humble people have much in common with wise people, such as being knowledgeable and insightful. Nevertheless, the former has some specific features, such as humility, open-mindedness, love of learning, and politeness. These features are distinct from the image of wise people or intellectually arrogant people reported by laypeople.

Regarding personality, most empirical studies consistently demonstrated that intellectually humble people are high in agreeableness, conscientiousness, openness, and emotional stability, and have a greater need for cognition and curiosity (Davis et al., 2016; Haggard et al., 2018; Hoyle et al., 2016; Krumrei-Mancuso, Haggard, LaBouff, \& Rowatt, 2020; McElroy et al., 2014; Meagher et al., 2015; Porter \& Schumann, 2018). Furthermore, they are more tolerant of the ambiguous, and less closed-minded and dogmatic (Haggard et al., 2018; Hoyle et al., 2016). The research using informant-report measure also showed that the perception of others' IH is positively related to the perception of that person's agreeableness, openness, conscientiousness, and emotional stability (McElroy et al., 2014). Moreover, people high in IH are more self-confident, capable, honest, funny, and favorable. They are also good leaders and have more authentic pride (Haggard et al., 2018; Meagher et al., 2015).

As for mindset, people high in $\mathrm{IH}$ are more rational and objective. They are good at reflective and open-minded thinking, have more intellectual engagement, and are more tolerant of others' ideas (Krumrei-Mancuso et al., 2020; Krumrei-Mancuso \& Rouse, 2016). They also have lower religious ethnocentrism. That is, they do not perceive their views as morally superior to other groups' views (Davis et al., 2016). They are less radical in their stances (no mat- 
ter what directions these positions take); they are less confident that their opinions are correct, and they do not perceive that their thoughts more valuable than other people's thoughts. They are also receptive to others' ideas and prefer balanced perspectives as opposed to one-sided perspectives. They can distinguish reliable and valid evidence from weak and ungrounded evidence. Finally, intellectually humble people have a more positive attitude towards people who have ever changed positions (Leary et al., 2017).

\section{Factors that Influence IH}

Generally, the interpersonal difference in IH may derive from the difference in cognitive ability and motivation. Regarding information processing and cognitive ability, the higher the cognitive ability a person possesses (e.g., can distinguish what they know and what they do not know), the higher his IH is (Deffler, Leary, \& Hoyle, 2016). Regarding motivation, people who want to get new and accurate knowledge may have a higher IH (Leary et al., 2017). On the other hand, people who want to defend their ego may have low IH because they are worried that new knowledge will reveal their ignorance (Gregg, Sedikides, \& Gebauer, 2011).

\subsection{Factors Influencing Trait IH}

\subsubsection{Cognitive Ability and Intelligence}

In general, the more knowledge a person lacks, the more he/she cannot be aware of and admit his/her ignorance; this is called the Dunning-Kruger effect (Dunning, 2011). Therefore, cognitive ability and intelligence may be a crucial factor influencing IH.

According to dual-process theories of human cognition, people's cognitive activities rely on two different systems (Samuelson \& Church, 2015). System 1 does not require conscious attention; it is impulsive, intuitive, rapid, and relies mainly on heuristics. On the contrary, System 2 needs conscious attention; it is rational, deliberative, slow, and relies on algorithm and reflection (they may correspond to trait and state IH separately). The biases and misjudgments about one's ability and knowledge may be attributed to an over-reliance on System 1 processing or anomalies of System 2. Therefore, if someone wants to have a high IH, his System 2 process needs to function more than his System 1 process. In order to execute algorithm and reflection in System 2 effectively, some extent of cognitive ability and intelligence are necessary.

As indirect evidence, De Keersmaecker \& Roets (2017) showed that in comparison to people with lower cognitive ability, people with higher cognitive ability had a greater tendency to change their attitude after recognizing that their previous attitude of themselves was based on false information. Zmigrod, Zmigrod, Rentfrow, \& Robbins (2019) demonstrated that both cognitive flexibility and intelligence predict $\mathrm{IH}$, and there is no overlap between their effects. This result means that each of them is sufficient for high IH. Research in developmental psychology also showed that children with high intelligence have higher 
IH after controlling age, and this connection is specific to the cognitive aspect of IH, but not its social aspect (Danovitch et al., 2019).

\subsubsection{Mindset}

Some beliefs or mindset may also influence IH. For example, in comparison to people who believe that intelligence is constant (entity theories of intelligence), people who believe that intelligence can grow and evolve (incremental theories of intelligence) have higher IH (Porter \& Schumann, 2018). This belief may promote the non-defensive orientation toward one's intelligence, and this kind of promotion has been proven applicable to state IH by experimental research. Furthermore, people who were required to think about a problem from a distanced perspective have higher IH (Kross \& Grossmann, 2012). This result may imply that people who have an abstract mindset (Trope \& Liberman, 2010) or have a high level of personal agency (Vallacher \& Wegner, 1989) may have high IH.

\subsubsection{Self-Esteem}

Some extent of psychological adjustment and self-esteem is necessary for IH because admitting one's inadequacies may threaten his or her self-esteem (Alfano et al., 2017). Therefore, a person with low self-esteem cannot judge his inadequacies objectively and will tend to adopt self-enhancement strategies to maintain or enhance positive self-evaluation (Gregg et al., 2011).

\subsection{Factors Influencing State IH}

\subsubsection{Attachment and Affect State}

Compared to people with an avoidant attachment style, those with secure attachment style are more open to new ideas. Furthermore, compared to people primed in anxious/ambivalent attachment condition, people primed in a secure attachment condition are more receptive to opinions differing from their own. In addition, people who experience more positive affect in their interpersonal relationships are more open (Jarvinen \& Paulus, 2016). These results implied that insecure attachment or negative affect experienced in interpersonal interactions might exacerbate the rejection of contrary opinion and its negative effects. These rejections may thwart the person's willingness to reflect and reason carefully and lead to defensive cognitive closure and eventually low IH.

\subsubsection{Factors in Interpersonal Relationship}

Since IH has interpersonal roots, some factors relevant to interpersonal interaction may affect IH. Two indicators have shown that in comparison with private settings, people in social settings have higher IH. Firstly, people in social settings reported higher IH than in nonsocial settings (Grossmann, Gerlach, \& Denissen, 2016). Secondly, after reflecting on challenges faced by others rather than on personal challenges, people tend to have higher IH (Grossmann \& Kross, 2014; Kross \& Grossmann, 2012).

Moreover, in social situations, some factors can influence IH. Firstly, the 
attributes of others may affect $\mathrm{IH}$, such as intelligence. It has been demonstrated that when another person is more intelligent, people are more open (Jarvinen \& Paulus, 2016). Secondly, the features of the relationship play an important role in IH. Daily diary studies showed that in comparison with situations where strangers were present, people have higher $\mathrm{IH}$ in situations where friends and colleagues were present (Grossmann et al., 2016). Thirdly, the other's attitude can affect $\mathrm{IH}$. When people recognized that others or social environments are responsive (e.g., they feel validated, understood, and cared for by others) rather than unresponsive to them, their IH was enhanced. It is because this kind of responsiveness abates people's defensive need to enhance their sense of self-worth (Reis, Lee, O'Keefe, \& Clark, 2018).

In a nutshell, people's $\mathrm{IH}$ is enhanced when they are in a secure and relaxed state.

\section{Psychological Functioning}

Admittedly, an optimistic judgment about ability and knowledge of oneself may improve one's self-esteem and self-efficacy, which, in turn, may improve performance in real tasks and buffer negative impacts (Bandura, 1997). However, excessive pretense or being not able to evaluate one's own ability accurately may lead to reluctance in seeking others' help or accepting new and better ideas (Danovitch et al., 2019). More importantly, pretense and arrogance may give rise to various interpersonal problems (Peters, Rowat, \& Johnson, 2011).

On the one hand, when in disagreement, people high in $\mathrm{IH}$ are more willing to expose themselves to and learn about contrary opinions. They are also more friendly and open-minded to contradictions (Porter \& Schumann, 2018). When faced with challenges, they report more positive and less negative emotions and exhibit more adaptive patterns of emotion regulation, greater emotional complexity, and more forgiveness (Grossmann et al., 2016).

On the other hand, as a social oil, IH can prevent and improve upon relational wear-and-tear. Intellectual arrogance may harm relationships, while IH may promote cooperation and interpersonal relationships. Firstly, regarding interpersonal perception, young children's evaluations of intellectually humble people and those who are intellectually arrogant are not significantly different; however, older children and adults prefer people high in IH and consider them to be nicer and smarter (Hagá \& Olson, 2017). The perception of high IH was related to trust and forgiveness. People high in IH were benevolent and did not seek revenge on others. These results imply that $\mathrm{IH}$ is an essential criterion in interpersonal perception and judgment (Hook et al., 2015; McElroy et al., 2014). Furthermore, intellectually humble people have some psychological attributes which may improve the interpersonal relationship. For example, people high in IH respect others' opinions, and they have a higher capacity for empathy. They genuinely accept others' conflicting opinions and see these opinions as ways to complement or modify their own; therefore, they have a higher sense of grati- 
tude. Their capacity for empathy and gratitude may further lead to prosocial value, such as altruism, benevolence, universalism (a broader focus on the welfare of all people and even nature), and lower levels of power-seeking (Krumrei-Mancuso, 2016). Moreover, IH was negatively related to social vigilantism so that it can enhance collaborative learning (Krumrei-Mancuso et al., 2020).

\section{Conclusions and Future Directions}

As reviewed above, many researchers have assumed that $\mathrm{IH}$ is a multidimensional psychological attribute constituted of multiple components. They also have developed corresponding scales to measure these components. On the one hand, this research status demonstrates the complexity of this psychological attribute and demonstrates that researchers have shown interest in this emerging research area. On the other hand, it suggests that in future studies, we should clarify the relationship among these components and find the essential feature of IH.

Relationships between $\mathrm{IH}$ and other psychological and social attributes have been widely studied. Research on these relationships has somewhat consistent results, such as the relationship between IH and Big Five; however, some inconsistent results need to be investigated further. For example, general IH was related to better academic achievement in some cases (Rowatt et al., 2006) and a low GPA in other cases (Krumrei-Mancuso et al., 2020). Research on the relationship between intellectual arrogance and academic performance also showed a positive (Meagher et al., 2015) and a negative (Zakay \& Glicksohn, 1992) correlation. Ascertaining the relationship between $\mathrm{IH}$ and task performance or academic achievement helps ascertain which of the following factors mainly affects IH: cognitive ability and intelligence, accurate meta-cognitive ability, and virtue. Current research on this issue is almost correlational design. This kind of research could not demonstrate the direction of causality, which is especially important to solve this problem. Hence, researchers should resort to longitudinal or experimental design.

Furthermore, the correlation between self- and informant-reported IH is low (Alfano et al., 2017; Meagher et al., 2015), and self-reported IH was related to self-enhancement biases. These two results suggest that judgments of others' IH and one's own IH may be based on different mechanisms. The former may be mainly influenced by accuracy in person perception, but the latter may be highly influenced by social desirability bias (Meagher et al., 2015). However, as Alfano et al. (2017) analyzed, this inconsistency may be only because some attributes of IH lead informants have worse or different epistemic access than a person oneself, or individuals may explain items in the IH scale differently. Further research should test these assumptions to investigate the mechanism of IH judgment.

\section{Conflicts of Interest}

The authors declare no conflicts of interest regarding the publication of this paper. 


\section{References}

Alfano, M., Iurino, K., Stey, P., Robinson, B., Christen, M., Yu, F., \& Lapsley, D. K. (2017). Development and Validation of a Multi-Dimensional Measure of Intellectual Humility. PLoS ONE, 12, e0182950. https://doi.org/10.1371/journal.pone.0182950

Baehr, J. (2011). The Inquiring Mind. New York: Oxford University Press.

Bandura, A. (1997). Self-Efficacy: The Exercise of Control. New York: Freeman.

Chancellor, J., \& Lyubomirsky, S. (2013). Humble Beginnings: Current Trends, State Perspectives, and Hallmarks of Humility. Social and Personality Psychology Compass, 7, 819-833. https://doi.org/10.1111/spc3.12069

Danovitch, J. H., Fisher, M., Schroder, H. M., Hambrick, D. Z., \& Moser, J. (2019). Intelligence and Neurophysiological Markers of Error Monitoring Relate to Children's Intellectual Humility. Child Development, 90, 924-939.

https://doi.org/10.1111/cdev.12960

Davis, D. E., Hook, J. N., Worthington, E. L., Van Tongeren, D. R., Gartner, A. L., \& Jennings, D. J. (2010). Relational Spirituality and Forgiveness: Development of the Spiritual Humility Scale (SHS). Journal of Psychology and Theology, 38, 91-100. https://doi.org/10.1177/009164711003800202

Davis, D. E., Hook, J. N., Worthington, E. L., Van Tongeren, D. R., Gartner, A. L., Jennings, D. J., \& Emmons, R. A. (2011). Relational Humility: Conceptualizing and Measuring Humility as a Personality Judgment. Journal of Personality Assessment, 93, 225-234. https://doi.org/10.1080/00223891.2011.558871

Davis, D. E., Rice, K. G., McElroy, S. E., DeBlaere, C., Choe, E., Van Tongeren, D. R., \& Hook, J. N. (2016). Distinguishing Intellectual Humility and General Humility. The Journal of Positive Psychology, 11, 215-224. https://doi.org/10.1080/17439760.2015.1048818

De Keersmaecker, J., \& Roets, A. (2017). "Fake News": Incorrect, but Hard to Correct. The Role of Cognitive Ability on the Impact of False Information on Social Impressions. Intelligence, 65, 107-110. https://doi.org/10.1016/j.intell.2017.10.005

Deffler, S. A., Leary, M. R., \& Hoyle, R. H. (2016). Knowing What You Know: Intellectual Humility and Judgments of Recognition Memory. Personality and Individual Differences, 96, 255-259. https://doi.org/10.1016/j.paid.2016.03.016

Dunning, D. (2011). The Dunning-Kruger Effect: On Being Ignorant of One's Own Ignorance. In J. M. Olson, \& M. P. Zanna (Eds.), Advances in Experimental Social Psychology (Vol. 44, pp. 247-296). Cambridge, MA: Academic Press. https://doi.org/10.1016/B978-0-12-385522-0.00005-6

Gregg, A., Sedikides, C., \& Gebauer, J. (2011). Dynamics of Identity: Between Self-Enhancement and Self-Assessment. In S. J. Schwartz, K. Luyckx, \& V. L. Vignoles (Eds.), Handbook of Identity: Theory and Research (Vol. 1, pp. 305-327). New York: Springer. https://doi.org/10.1007/978-1-4419-7988-9_14

Grossmann, I., \& Kross, E. (2014). Exploring Solomon's Paradox: Self-Distancing Eliminates the Self-Other Asymmetry in Wise Reasoning about Close Relationships in Younger and Older Adults. Psychological Science, 25, 1571-1580. https://doi.org/10.1177/0956797614535400

Grossmann, I., Gerlach, T. M., \& Denissen, J. J. A. (2016). Wise Reasoning in the Face of Everyday Life Challenges. Social Psychological and Personality Science, 7, 611-622. https://doi.org/10.1177/1948550616652206

Hagá, S., \& Olson, K. R. (2017). "If I Only Had a Little Humility, I Would Be Perfect": Children's and Adults' Perceptions of Intellectually Arrogant, Humble, and Diffident 
People. The Journal of Positive Psychology, 12, 87-98.

https://doi.org/10.1080/17439760.2016.1167943

Haggard, M. C. (2016). Humility as Intellectual Virtue: Assessment and Uses of a Limitations-Owning Perspective of Intellectual Humility. Ph.D. Thesis, Ann Arbor, MI: Baylor University.

Haggard, M. C., Rowatt, W. C., Leman, J. C., Meagher, B. R., Moore, C., Fergus, T. et al. (2018). Finding Middle Ground between Intellectual Arrogance and Intellectual Servility: Development and Assessment of the Limitations-Owning Intellectual Humility Scale. Personality and Individual Differences, 124, 184-193. https://doi.org/10.1016/j.paid.2017.12.014

Hazlett, A. (2012). Higher-Order Epistemic Attitudes and Intellectual Humility. Episteme, 9, 205-223. https://doi.org/10.1017/epi.2012.11

Hook, J. N., Davis, D. E., Owen, J., Worthington Jr., E. L., \& Utsey, S. O. (2013). Cultural Humility: Measuring Openness to Culturally Diverse Clients. Journal of Counseling Psychology, 60, 353-366. https://doi.org/10.1037/a0032595

Hook, J. N., Davis, D. E., Van Tongeren, D. R., Hill, P. C., Worthington, E. L., Farrell, J. E., \& Dieke, P. (2015). Intellectual Humility and Forgiveness of Religious Leaders. The Journal of Positive Psychology, 10, 499-506. https://doi.org/10.1080/17439760.2015.1004554

Hoyle, R. H., Davisson, E. K., Diebels, K. J., \& Leary, M. R. (2016). Holding Specific Views with Humility: Conceptualization and Measurement of Specific Intellectual Humility. Personality and Individual Differences, 97, 165-172. https://doi.org/10.1016/j.paid.2016.03.043

Jarvinen, M. J., \& Paulus, T. B. (2016). Attachment and Cognitive Openness: Emotional Underpinnings of Intellectual Humility. The Journal of Positive Psychology, 12, 74-86. https://doi.org/10.1080/17439760.2016.1167944

Kross, E., \& Grossmann, I. (2012). Boosting Wisdom: Distance from the Self Enhances Wise Reasoning, Attitudes, and Behavior. Journal of Experimental Psychology: General, 141, 43-48. https://doi.org/10.1037/a0024158

Krumrei-Mancuso, E. J. (2016). Intellectual Humility and Prosocial Values: Direct and Mediated Effects. The Journal of Positive Psychology, 12, 13-28. https://doi.org/10.1080/17439760.2016.1167938

Krumrei-Mancuso, E. J., \& Rouse, S. V. (2016). The Development and Validation of the Comprehensive Intellectual Humility Scale. Journal of Personality Assessment, 98, 209-221. https://doi.org/10.1080/00223891.2015.1068174

Krumrei-Mancuso, E. J., Haggard, M. C., LaBouff, J. P., \& Rowatt, W. C. (2020). Links between Intellectual Humility and Acquiring Knowledge. The Journal of Positive Psychology, 15, 155-170. https://doi.org/10.1080/17439760.2019.1579359

Leary, M. R., Diebels, K. J., Davisson, E. K., Jongman-Sereno, K. P., Isherwood, J. C., Raimi, K. T. et al. (2017). Cognitive and Interpersonal Features of Intellectual Humility. Personality and Social Psychology Bulletin, 43, 793-813. https://doi.org/10.1177/0146167217697695

McElroy, S. E., Rice, K. G., Davis, D. E., Hook, J. N., Hill, P. C., Worthington, E. L., \& Van Tongeren, D. R. (2014). Intellectual Humility: Scale Development and Theoretical Elaborations in the Context of Religious Leadership. Journal of Psychology and Theology, 42, 19-30. https://doi.org/10.1177/009164711404200103

Meagher, B. R., Leman, J. C., Bias, J. P., Latendresse, S. J., \& Rowatt, W. C. (2015). Contrasting Self-Report and Consensus Ratings of Intellectual Humility and Arrogance. Journal of Research in Personality, 58, 35-45. https://doi.org/10.1016/j.jrp.2015.07.002 
Peters, A., Rowat, W., \& Johnson, M. (2011). Associations between Dispositional Humility and Social Relationship Quality. Psychology, 2, 155-161.

https://doi.org/10.4236/psych.2011.23025

Porter, T., \& Schumann, K. (2018). Intellectual Humility and Openness to the Opposing View. Self and Identity, 17, 139-162. https://doi.org/10.1080/15298868.2017.1361861

Reis, H. T., Lee, K. Y., O’Keefe, S. D., \& Clark, M. S. (2018). Perceived Partner Responsiveness Promotes Intellectual Humility. Journal of Experimental Social Psychology, 79, 21-33. https://doi.org/10.1016/j.jesp.2018.05.006

Rowatt, W. C., Powers, C., Targhetta, V., Comer, J., Kennedy, S., \& LaBouff, J. P. (2006). Development and Initial Validation of an Implicit Measure of Humility Relative to Arrogance. The Journal of Positive Psychology, 1, 198-211.

https://doi.org/10.1080/17439760600885671

Samuelson, P. L., \& Church, I. M. (2015). When Cognition Turns Vicious: Heuristics and Biases in Light of Virtue Epistemology. Philosophical Psychology, 28, 1095-1113. https://doi.org/10.1080/09515089.2014.904197

Samuelson, P. L., Jarvinen, M. J., Paulus, T. B., Church, I. M., Hardy, S. A., \& Barrett, J. L. (2015). Implicit Theories of Intellectual Virtues and Vices: A Focus on Intellectual Humility. The Journal of Positive Psychology, 10, 389-406.

https://doi.org/10.1080/17439760.2014.967802

Tangney, J. P. (2000). Humility: Theoretical Perspectives, Empirical Findings and Directions for Future Research. Journal of Social and Clinical Psychology, 19, 70-82. https://doi.org/10.1521/jscp.2000.19.1.70

Trope, Y., \& Liberman, N. (2010). Construal-Level Theory of Psychological Distance. Psychological Review, 117, 440-463. https://doi.org/10.1037/a0018963

Vallacher, R. R., \& Wegner, D. M. (1989). Levels of Personal Agency: Individual Variation in Action Identification. Journal of Personality and Social Psychology, 57, 660-671. https://doi.org/10.1037/0022-3514.57.4.660

Wang, J., \& Yang, X. (2019). Intellectual Humility and Owning One's Limitations. Fudan Journal of the Humanities and Social Sciences, 12, 353-369. https://doi.org/10.1007/s40647-019-00260-8

Whitcomb, D., Battaly, H., Baehr, J., \& Howard-Snyder, D. (2017). Intellectual Humility: Owning Our Limitations. Philosophy and Phenomenological Research, 94, 509-539. https://doi.org/10.1111/phpr.12228

Wright, J. C., Nadelhoffer, T., Perini, T., Langville, A., Echols, M., \& Venezia, K. (2017). The Psychological Significance of Humility. The Journal of Positive Psychology, 12, 3-12. https://doi.org/10.1080/17439760.2016.1167940

Zachry, C. E., Phan, L. V., Blackie, L. E. R., \& Jayawickreme, E. (2018). Situation-Based Contingencies Underlying Wisdom-Content Manifestations: Examining Intellectual Humility in Daily Life. The Journals of Gerontology: Series B, 73, 1404-1415. https://doi.org/10.1093/geronb/gby016

Zakay, D., \& Glicksohn, J. (1992). Overconfidence in a Multiple-Choice Test and Its Relationship to Achievement. The Psychological Record, 42, 519-524. https://doi.org/10.1007/BF03399619

Zmigrod, L., Zmigrod, S., Rentfrow, P. J., \& Robbins, T. W. (2019). The Psychological Roots of Intellectual Humility: The Role of Intelligence and Cognitive Flexibility. Personality and Individual Differences, 141, 200-208.

https://doi.org/10.1016/j.paid.2019.01.016 